\title{
Intensive care management in brain contusion with microdialysis technique
}

\author{
Aplicação da técnica de microdiálise no manejo de contusão cerebral \\ Almir Ferreira De Andrade1, Wellingson Silva Paiva², Marcelo Prudente², Luca Bernardo², Manoel Jacobsen Teixeira ${ }^{3}$ \\ Division of Neurosurgery, Hospital das Clínicas, University of São Paulo Medical School, São Paulo SP, Brazil. \\ ${ }^{1} \mathrm{MD}$, PhD; Director of Neurosurgical Emergency Unit; \\ ${ }^{2} \mathrm{MD}$; Staff; \\ ${ }^{3} \mathrm{MD}$, PhD; Professor of Neurosurgery and Chairman. \\ Correspondence: Wellingson Paiva; Rua Enéas Aguiar 255/4.080; 05406-000 São Paulo SP - Brasil; E-mail: wellingsonpaiva@yahoo.com.br \\ Conflict of interest: There is no conflict of interest to declare. \\ Received 12 January 2012; Received in final form 27 March 2012; Accepted 03 April 2012
}

Several pathophysiological processes triggered by brain contusion in severe head trauma have special significance, and metabolic disturbances play an important role $e^{1,2}$. High concentrations of neurotransmitters and other substances are released after traumatic brain injuries, and microdialysis has been described to study these neurochemistry disturbances. We applied this technique on a patient with brain contusion for postoperative monitoring and intensive management guidance.

\section{CASE REPORT}

Patient admitted to the emergency room following a car accident, Glasgow Coma Scale (GCS) score was 12, without deficits or systemic lesions. Skull computed tomography (Figs A to C) showed frontotemporal contusion with mild cerebral edema. Brain hematoma drainage was performed and two transcranial bolts were introduced in the ventricle for intracranial pressure (ICP) measure, and at the penumbra area surrounding the hematoma a microdialysis catheter (CMA 70, CMA AB, Stockholm, Sweden) was also introduced. Samples for analysis of glucose, pyruvate, lactate, and glycerol were collected every 60 minutes.

In the first day, the ICP was $12 \mathrm{mmHg}$, but lactate-pyruvate ratio was raised (35.7), which indicated early ischemia/ intracranial hypertension. We opened the system with external ventricular drainage and hypothermia was performed with substantial improvement in the subsequent evaluations. Glycerol remained elevated during the monitoring period. In the second day, we verified elevation of glutamate and reduction of glucose. These metabolic disorders improved with optimization of ventilation and hypothermia, maintaining adequate blood pressure and perfusion pressure (Fig D). After six months, the patient presented moderate disability. 

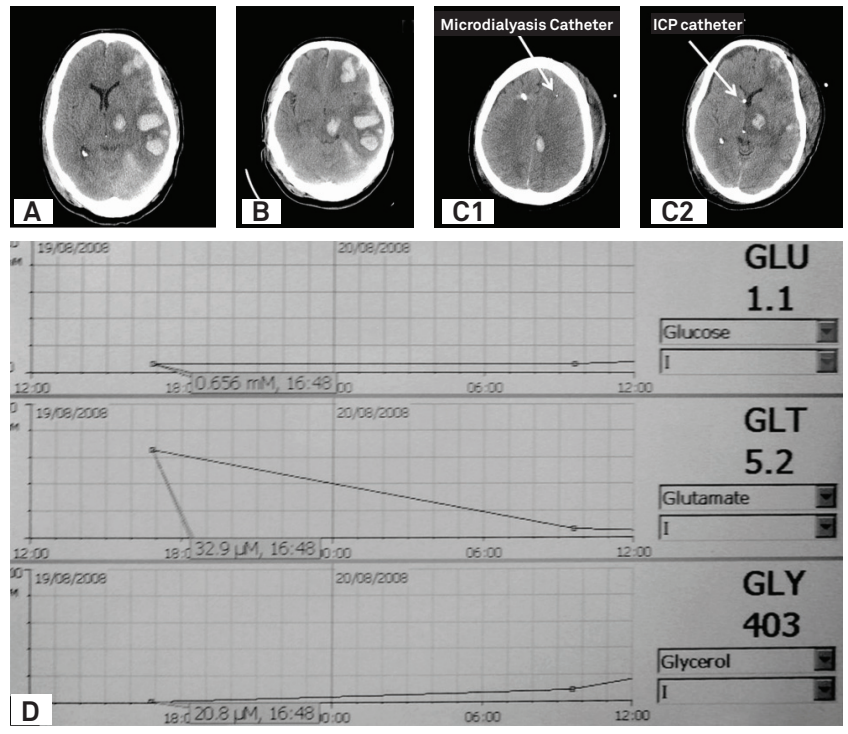

ICP: intracranial pressure.

Fig. Skull computed tomography with brain hematoma. (A) First tomography; (B) second tomography; (C) postoperative tomography (C1) slice with intracranial pressure catheter (C2) slice with microdialysis catheter; (D) metabolic disorders improved with optimization of ventilation and hypothermia, maintaining adequate blood and perfusion pressures.

\section{DISCUSSION}

The microdialysis technique allows a better understanding of secondary insults and description of changes in cerebral metabolism before cessation of blood flow ${ }^{2}$, other monitoring methods usually do not reveal the consequences of secondary adverse events until large parts of the brain are affected ${ }^{2}$.
Glucose is the energy source of the brain ${ }^{3}$. Lactate and the lactate-pyruvate ratio relate to the extent of glycolysis and anaerobic metabolism. High level of lactate might be caused by hypoxia/ischemia, but increased glycolysis can also be. The lactate-pyruvate ratio distinguishes between these conditions. Pyruvate production falls during ischemia, which causes variations in the lactate-pyruvate ratio ${ }^{3}$. The increased concentration of glutamate results from the depolarization of membranes and from decreased reuptake mechanism, which activates postsynaptic receptors resulting in cellular edema, leading to cell death ${ }^{3}$. Glycerol has been used as a compound signaling cellular damage. We have seen massive increases in extracellular glycerol during ischemia, hypoxia, and infections in human as well as animal brain ${ }^{3}$.

After brain hematoma drainage, we believe that ICP monitoring guides the treatment with intensive measures, however it is possible that it alone is not sufficient, therefore the neurochemical monitoring adds information to treat these patients. In our patient we decided to perform hypothermia Wang et al. ${ }^{4}$, in an experimental study, described the effect of mild hypothermia on glucose metabolism and glycerol by microdialysis.

The present state of the microdialysis application to brain-injured patients has been summarized as a research tool $^{5}$. Origins of variations between microdialysis measures and the state of the patient need to be clarified, however we believe that microdialysis results helped us in treating brain metabolic disorders and allowed to establish measures for cerebral protection, which possibly interfered in the final clinical outcome of our patient.

\section{References}

1. Andrade AF, Paiva WS, Amorim RL, Figueiredo EG, Rusafa Neto E, Teixeira MJ. The pathophysiological mechanisms following traumatic brain injury. Rev Assoc Med Bras 2009;55:75-81.

2. Ståhl N, Nordström $\mathrm{CH}$. Brain energy metabolism during controlled reduction of cerebral perfusion pressure in severe head injuries. Intensive Care Med 2001;27:1215-1223.

3. Vespa PM. Intensive glycemic control in traumatic brain injury: what is the ideal glucose range? Crit Care 2008;12:175.
Wang Q, Li AL, Zhi DS, Huang HL. Effect of mild hypothermia on glucose metabolism and glycerol of brain tissue in patients with severe traumatic brain injury. Chin J Traumatol 2007;10:246-249.

5. Tisdall MM, Smith M. Cerebral microdialysis: research technique or clinical tool. Br J Anaesthesia 2006;97:18-25. 